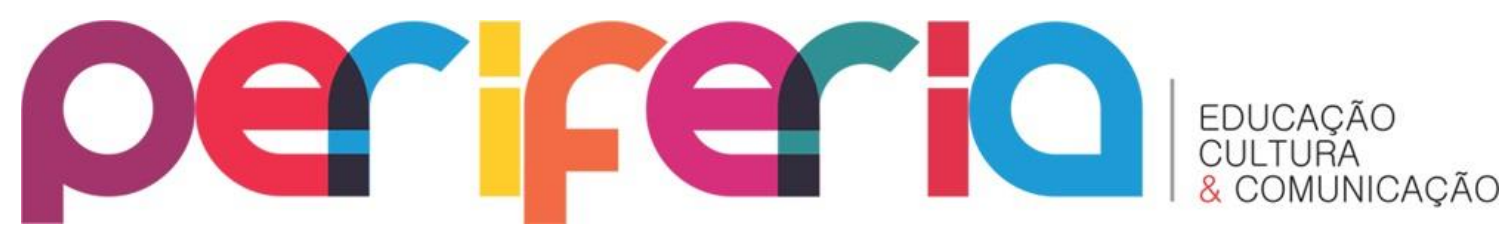

\title{
BRINCAR NA INFÂNCIA PLURAL: DA EDUCAÇÃO JESUÍTA AO ESTUDO DA LUDICIDADE
}

\section{TO PLAY IN PLURAL CHILDREN: FROM JESUIT EDUCATION TO THE STUDY OF DECEIT}

\author{
Jonathan Machado Domingues ${ }^{1}$
}

\begin{abstract}
Resumo: O presente trabalho tem como objetivo contextualizar o universo plural da infância, o brincar e a questão educacional e curricular de maneira sucinta. Brincar, ação está praticada e realizada por todos os componentes sociais. Assim sendo, é atingível afirmar que cada grupo social, nos parâmetros espacial referindo o meio que se encontra, tem/prática brincadeira exclusiva e/ou a mesma brincadeira em várias localidades. Como exemplificação os nomes titulados ou as regras destas são diferenciados de lugar para lugar, em função da cultura local, cultura lúdica. Igualmente, como objetivo secundário será tratada a questão educacional jesuítica no período Colonial no Brasil. De resto, serão abordadas as questões históricas da infância juntamente com a formação do corpo docente ligado à finalidade da escola tanto para a classe mais rica quanto para a mais pobre. Tendo em vista que a palavra infância e família, tal como sabemos hoje, são sentimentos criados pela burguesia. Portanto, a elaboração desta pesquisa foi primordial interpretações de periódicos, livros e participação em congressos que tinham como temática a ludicidade. Outrossim, aos referenciais metodológicos, os principais utilizados foram: ALVARÉS E VARELA (1992), ARIÈS (1981), BROUGÈRE (1998),GADOTTI (2003), HUIZINGA (2004), PROUT (2010) e VASCONCELLOS (2008). Portanto, podemos concluir que o brincar vai além de um simples entretenimento. Trata-se de um estágio de preparação da criança para a vida adulta com a utilização da construção do simbólico, relacionado ao brinquedo, como ferramenta.
\end{abstract}

Palavras-chave: Infâncias; Lúdico; Formação do Docente; Educação

Abstract: The present work aims to contextualize the plural universe of childhood, play and the educational and curricular question in a succinct way. Play, action is practiced and performed by all social components. Therefore, it is possible to affirm that each social group, in the spatial parameters (to which the environment refers) that is, has / practice exclusive play and / or the same play in several localities. As an example, the

\footnotetext{
${ }^{1}$ Graduando de Pedagogia pela Faculdade de Educação da Universidade do Estado do Rio de Janeiro (2016) e História, licenciatura, pela Universidade Estácio de Sà (2017). Tendo como campo de pesquisa estudos das infâncias e currículo no que tange as séries iniciais. Atualmente, faz Estágio Interno Complementar na Universidade do Estado do Rio de Janeiro. Sendo bolsista na alocação da sub-reitoria de graduação. Tendo como orientadora/supervisora a sub-reitora de graduação, professora Dra $^{\mathrm{a}}$. Tania Maria de Castro Netto, com o PRIAAG- Projeto Interdisciplinar de Atenção a Alunos de Graduação/ UERJ em Processos Críticos.
} 


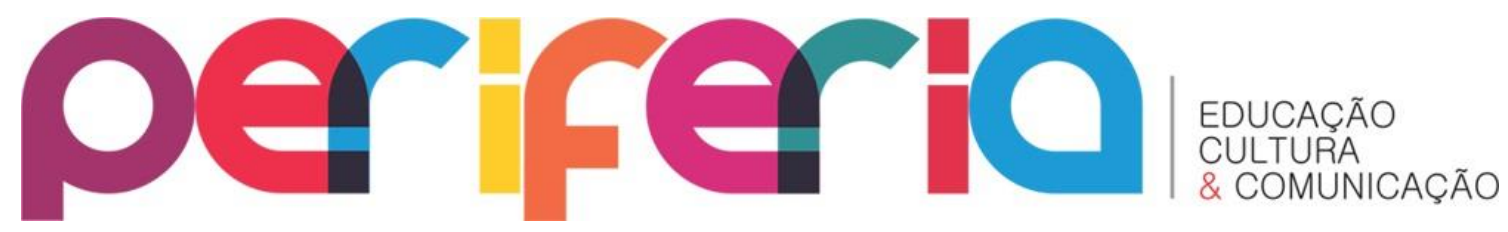

titled names or the rules of these are differentiated from place to place, depending on the local culture, ludic culture. Also, as secondary objective will be treated the Jesuit educational issue in the Colonial period in Brazil. In addition, the historical issues of childhood will be addressed together with the formation of the teaching staff connected to the purpose of the school for both the richest and the poorest classes. Since the word childhood and family, as we know it today, are feelings created by the bourgeoisie. Therefore, the elaboration of this research was primordial interpretations of periodicals, books and participation in congresses that had as subjects the playfulness. In addition, to the methodological references, the main ones used were: ALVARÉS E VARELA (1992), ARIÈS (1981), BROUGÈRE (1998), GADOTTI (2003), HUIZINGA (2004), PROUT (2010) and VASCONCELLOS (2008). Therefore, we can conclude that playing goes beyond simple entertainment. It is a stage of preparation of the child for adult life with the use of the construction of the symbolic, related to the toy, as a tool.

Keywords: Childhood; Playful; Teacher Training; Education.

\section{Dialogando através das imagens da (s) infância (s)}

Através dos estudos analisados desde ARIÈS à PROUT, será perceptível compreender as figuras da infância. Nota-se desde Idade Média até os dias atuais, houve/existiu/caracterizou uma fase, no qual cada época foi diferenciada com suas características.

Através de PROUT (2010), é atingível perceber no século XX como século da criança. Essa caracterização foi feita através da participação política que traduzira este grupo como projeto. Ademais, de acordo com VASCONCELLOS (2008, p.94):

\footnotetext{
"Nos anos de 1990 e que está vinculado, sem dúvida, às condições de vida das crianças e à inserção social da infância na contemporaneidade. Neste momento as crianças parecem tomar a cena da pesquisa, da mídia e da formação de opinião, o que leva a supor que é grande a preocupação e a importância que lhe são atribuídas. ” (Id)
}

Mesmo as crianças tendo um papel na sociedade, é nítido, através da análise de VASCONCELLOS (2008), que a infância é vítima de conflitos contemporâneos. Podendo citar como exemplo a prostituição, perseguição, fome, assassinatos, miséria, trabalho infantil, entre outras perseguições.

A infância é a preparação do sujeito infantil à vida adulta. Ademais, ainda VASCONCELLOS (2008, p.96): "é possibilidade, é potência. Como tal, a 


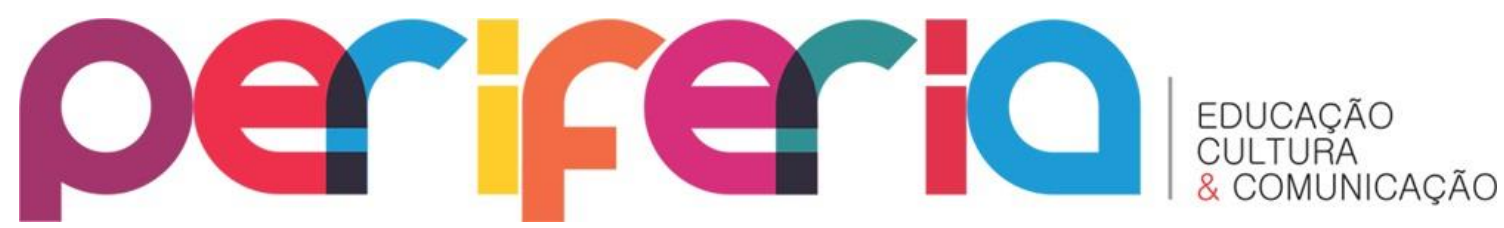

infância/potência é o objeto dos projetos educativos e políticos. As transformações sociais, nessa perspectiva, estão guardadas nas mãos destes que serão adultos e construtores do amanhã. ".

Contudo, a educação vem para ajudar a criança a vir a ser, pois ela é uma possibilidade. De acordo com DOMINGUES (2017, p.392):

\begin{abstract}
"O conceito Devir-Criança de Deluze faz refletir sobre uma criança que amanhã não será a mesma de hoje, pois ela sempre estará em transformação. Devemos deixar que a criança possa viver o tempo dela, ou seja, deixa-la ser criança. Apenas ser criança e não criarmos meios para que representem o futuro da sociedade. " (Id)
\end{abstract}

Como foi falado acima a respeito do devir- criança segundo Deleuze, onde houve o diálogo no que se refere à criança/infância como uma possibilidade. Pois todos os adultos, compreendem que este grupo (infância- fase; criança- sujeitos que compõem esta fase); será os adultos do amanhã, que podem trazer mudanças positivas tantos sociais, quanto políticas.

De resto, de acordo com KOHAN (2004, p.53): "a intervenção educacional tem um papel preponderante nessa linha continua. Ela se torna desejável e necessária na medida em que as crianças não têm um ser definido: elas são, sobretudo, possibilidades, potencialidades: elas serão o que devem ser.”. Todo o campo de pesquisa, no que tange a infância, tem como objetivos fundamentais compreender a infância como experiência infantil.

\footnotetext{
"Um desafio que se lança aos estudiosos da infância é pensar caminhos capazes de subtrair do termo infantil o caráter pejorativo e subestimado, que permitam ver a infância, não pelo que falta, mas que será quando não for mais infância, mas pelo que é; onde a infância não seja uma questão cronológica, mas a própria condição de experiência. " (VASCONCELLOS, 2008, p.98)
}

Igualmente, é atingível afirmar que o brinquedo possibilita além das realidades. Pois vemos uma tradução da infância como sujeito que não possui vez e acaba utilizando os brinquedos/brincadeiras para colocar em ação suas vontades, seu querer, sua opinião. Assim, através desta percepção que o brincar acaba dando autonomia à criança. De acordo com VYGOTSKY (1998, p.134-135): "No brinquedo, a criança sempre se comporta além do comportamento diário; no brinquedo é como se ela fosse 


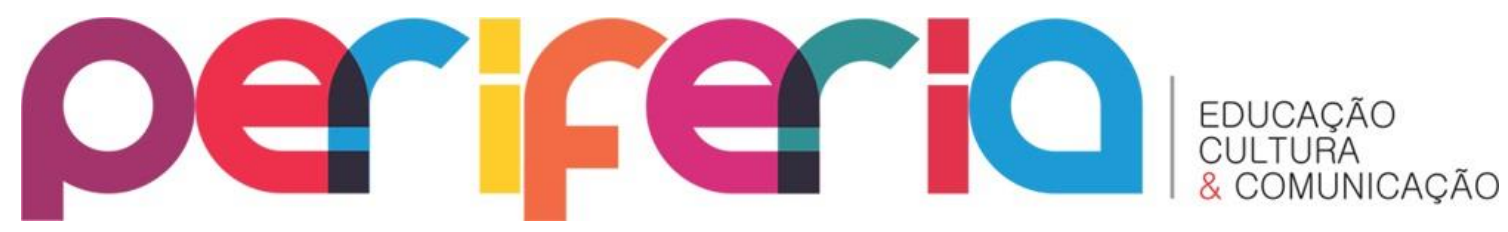

maior do que é na realidade.". De resto; o jogo são atividades sociais para toda sociedade, adultos, crianças. Segundo VASCONCELLOS (2008, p. 112):

“É de uso comum na atualidade a associação das idéias ideias de jogo e brincadeira à idéia ideia de criança. Como se o imenso patrimônio cultural dos jogos servisse apenas às atividades das crianças. Mas nem sempre foi assim. $\mathrm{Na}$ verdade, os jogos, como as demais atividades sociais, eram partilhados por toda a comunidade e a idéia ideia de infância como um período apartado da vida não tem mais que poucos séculos de existência." (Id)

$\mathrm{Na}$ fase contemporânea, o tempo e o espaço para brincar acabam sendo reduzidos com o passar do tempo. Segundo BORBA (2006, p.39):

\begin{abstract}
“(...) a brincadeira é um fenômeno da cultura, uma vez que se configura como um conjunto de práticas, conhecimentos e artefatos construídos e acumulados pelos sujeitos nos contextos históricos e sociais em que se inserem. Representa, dessa forma, um acervo comum sobre o qual os sujeitos desenvolvem atividades conjuntas. Por outro lado, o brincar é um dos pilares da constituição de culturas da infância, compreendidas como significações e formas de ação sociais específicas que estruturam as relações das crianças entre si, bem como os modos pelos quais interpretam, representam e agem sobre o mundo". (Id)
\end{abstract}

Cognoscível que o narrador ${ }^{2}$ pode transformar as suas vivências e as dos outros em histórias. Segundo BENJAMIN (1994, p. 221): "o narrador figura entre os mestres sábios. Ele sabe dar conselhos: não para alguns casos como provérbios, mas para muitos casos, como o sábio. (...). Seu dom é poder contar sua vida; sua dignidade é contá-la inteira."

\title{
2. Infância e Educação
}

Uma educação perfeita é para mim simbolizada por uma árvore plantada perto de águas fertilizantes. Uma pequena semente que contém o germe da árvore, sua forma e suas propriedades é colocada no solo. A árvore inteira é uma cadeia ininterrupta de partes orgânicas, cujo plano existia na semente e na raiz. O homem é como a árvore. Na criança recém-nascida estão ocultas as faculdades que lhe hão de desdobrar-se durante a vida: os órgãos do seu ser gradualmente se formam, em uníssono, e constroem a humanidade à imagem

\footnotetext{
${ }^{2}$ Narrador pode ser caracterizado como as crianças. Pois quando esses sujeitos acabam entrando num outro ambiente, como exemplo, dos adultos, acaba trazendo consigo modificações tanto do espaço quanto do tempo. Vai ter que haver de uma maneira diretamente uma adaptação da parte dos adultos para o ambiente infantil
} 


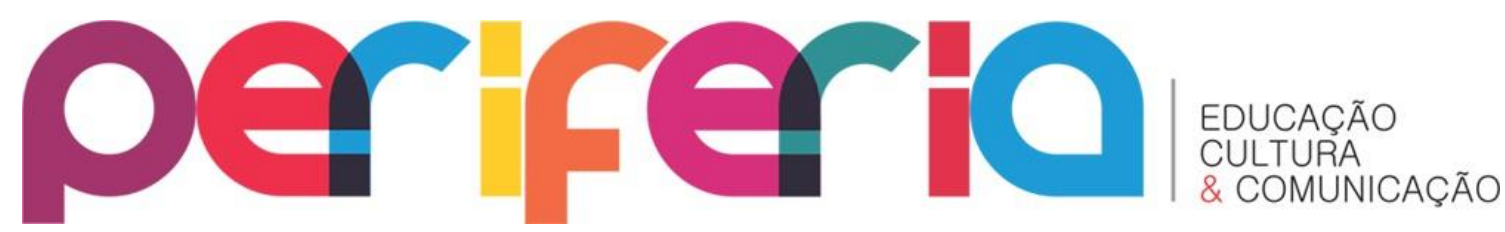

de Deus. A educação do homem é um resultado puramente moral (Pestalozzi in Gadotti, 1997).

O surgimento dos Estados Modernos, o renascimento cultural, e a Reforma e Contrarreforma, são de grande importância para a criação da maquinaria escolar. As elites tentam camuflar o verdadeiro papel da instituição escolar.

A escola constitui os pilares da posição hegemônica de classes dominantes.De acordo com VARELA e ALVAREZ (1992,p.68): " “a escola nem sempre existiu; daí a necessidade de determinar suas condições históricas de existência no interior de nossa formação social. A infância é uma instituição social, fruto de uma classe e de um Estado Nacional. Ainda segundo VARELA e ALVAREZ (1992,p 69): “Assim como a escola, a criança, tal como a percebemos atualmente, não é eterna nem natural; é uma instituição social de aparição recente ligada a práticas familiares, modos de educação e, consequentemente, a classes sociais. ".

Diante da formação dos Estados Nacionais, o Renascimento Cultural e a Reforma Protestante, a igreja se vê obrigada a reformular toda sua metodologia. Em busca de novos fiéis, a igreja coloca como alvo principal a infância e seus indivíduos, entendendo que essa idade tinha de ser moldada. Outrossim, a infância é uma idade a ser moldada através da escola.

\footnotetext{
"Configura-se, pois, a "meninice", no âmbito teórico e abstrato, como uma etapa especialmente idônea para ser moldada, marcada, uma vez que se justifica a necessidade de seu governo específico, que dará lugar à emergência de dispositivos institucionais concretos; e se, no final, a poderosa arte da educação fracassa, pode-se jogar a culpa na má índole dos sujeitos. ” (VARELA e ALVAREZ, 1992, p.72)
}

Portanto, é atingível afirmar que a escola servirá de laboratório para definição sobre o que é a infância. Dentro do processo de modelagem da infância, a família irá cumprir m papel de extrema importância. Segundo VARELA e ALVAREZ (1992, p.73): “os pequenos das classes poderosas ver-se-ão, assim, submetidos a duas tutelas, a da família e a do colégio, exercidas para seu próprio bem. Para os pobres uma bastalhes: a das instituições de caridade.“. Na Idade Média não existia a ideia de infância; 


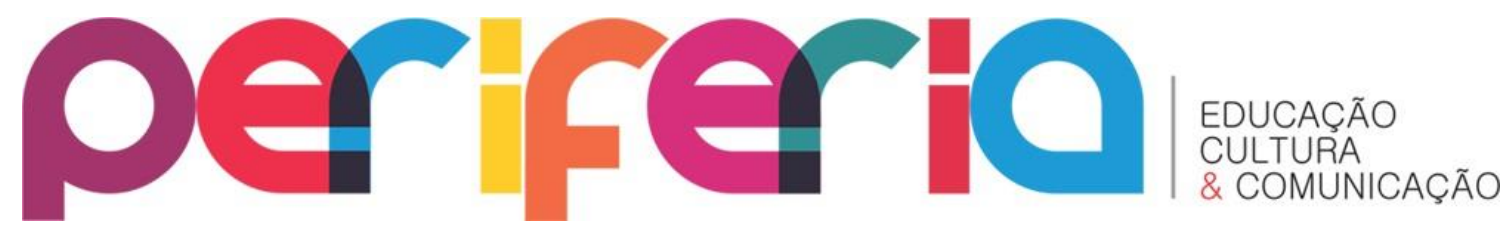

criança; desde que, tivesse condições plenas de ser valer por si mesma, integrava-se na sociedade assim como os adultos.

A distinção da infância em classes sociais, faz parte de um plano de dominação onde a criança rica é educada para mandar, enquanto a criança pobre é ensinada a obedecer. Só para deixar registrado que os termos infância e família são sentimentos criados pela burguesia. De acordo com ARIÈS (1981 p.11): “a escola substitui a aprendizagem como meio de educação. Isto quer dizer que a criança deixou de ser misturada aos adultos e de aprender a vida diretamente através do contato com eles". De resto, a criança não tem mais o seu processo de aprendizagem junto aos adultos.

A escolarização é, portanto, um processo de adestramento, onde, a criança sai “domesticada". A educação das classes populares se diferenciara da educação da elite pela forma de enclausuramento e didática que são consequência de uma valorização social de máxima repreensão e mínimo saber. A grande diferença, entre educação do pobre para o rico não se dá somente nos conteúdos ensinados, mas, nos castigos, os subestimemos as ordens e o distanciamento da autoridade.

\begin{abstract}
"Mas não se trata unicamente de diferenças de conteúdos e atividades; se não que a dureza do enclausuramento, o rigor dos castigos, o submestimentos às ordens, o distanciamento da autoridade, e a auto percepção que se lhes inculca são os frutos da diferença abismal que existe entre os preceptores domésticos, os colégios e "as escolas de primeiras letras" destinadas aos filhos dos pobres. "(VARELA e ALVAREZ, 1992, p.79)
\end{abstract}

Igualmente, é perceptível trazer aos dias atuais toda educação que o sujeito acaba recebendo/adquirindo; acaba tendo interferência de interesse da instituição. Instituição está que no meio/universo que se encontra é dividido em dois; público e privado. Pode-se usar como exemplificação um colégio público, onde os discentes receberão ensinamento que o Estado quer. Ou seja, o Estado, por exemplo, não quer seres pensantes que vá contra os seus posicionamentos. Ademais, a mesma imposição que é encontrada nos dias atuais pode comparar com a educação jesuítica no período do Brasil colonial.

A sociedade nos molda. A educação que recebemos tem por objetivo nos enquadrar as expectativas do meio social em que vivemos- nossa classe, nossa profissão, nosso meio moral. Cada geração transmite à seguinte, através da educação, os elementos fundamentais para a manutenção da estabilidade das coletividades humanas. (RODRIGUES, 2004, p. 31) 


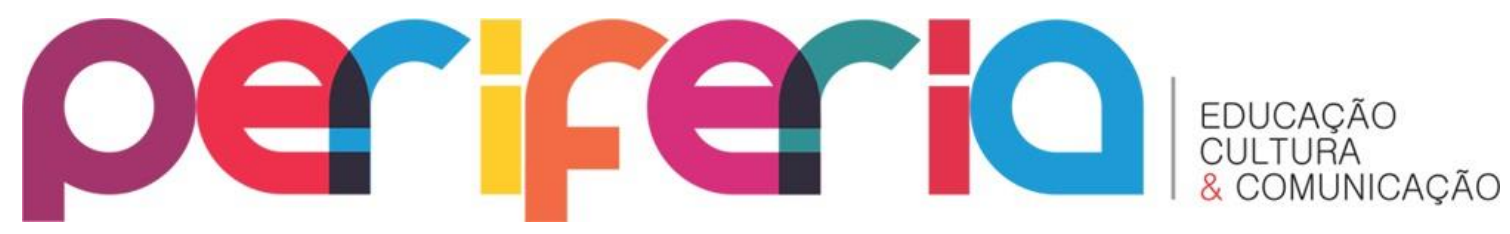

Ademais, continuando com o teórico RODRIGUES (2004, p.43), finalizando este capitulo ao que tange o tempo que a criança fica dentro da escola para iniciarmos ao que ser refere a educação jesuítica.

\begin{abstract}
Marx afirma, inclusive, que a escola em tempo integral é pouco produtiva, porque, não sendo combinada com o trabalho manual, torna o dia da criança enfadonho, o trabalho do professor mais duro e o rendimento escolar menor. "As crianças com escola de meio período e trabalho no outro período aprendem anto ou mais que as crianças que ficam na escola o dia todo", escreveu Marx. Para ele, uma vez conjugados o trabalho e a escola, uma atividade funcionaria como descanso para a outra. Mas o fundamental é que, através dessa conjugação, seria possível na visão de Marx romper, na formação das futuras gerações com a separação entre trabalho manual e intelectual e também com a parcialização das tarefas impostas pela divisão do trabalho na fábrica moderna. (Id)
\end{abstract}

Portanto, finalizo este capitulo com a teoria que criança deve ser criança. Devemos deixá-la criar e inventar novas maneiras de atividades lúdicas, pois assim o nível de aprendizagem é muito maior e prazeroso. Não deve existir imposição da parte dos docentes para o aprender. Mais sim, deixar acontecer para não colocar fardo aonde tem que haver felicidade e pleno gozo ao conhecimento. De acordo com DIOLIVEIRA $(2016, p .2)$

A educação promove efeitos em muitos aspectos na vida das pessoas. Além de sua ação em gerar maiores oportunidades para se conseguir um bom emprego, ela também oferece às pessoas a aprendizagem necessária para torná-las cidadãs ativas. Isso, portanto, é prova irrefutável de que a educação é uma "arma" com dois gumes importantes. (Id)

\title{
3. Educação no Brasil Colônia: Perspectiva Jesuítica em solo colonial português
}

A companhia de Jesus foi uma ordem fundada em 1543 pelo militar espanhol, burguês, Inácio de Loyola (1491 - 1556). Durante algum tempo, a pedagogia jesuítica exerceu grande influência em todo o mundo, incluindo o Brasil com a chegada da ordem em 1549. Os jesuítas vieram para o Brasil, acompanhando o primeiro governador geral Tomé de Souza e liderados por Manuel No ano de 1549, chegava ao nordeste do Brasil, no estado da Bahia a primeira expedição jesuítica. Tendo no seu desembarque o Governador-Geral Tomé de Sousa, que era chefiado pelo padre Manuel de Nobrega. 


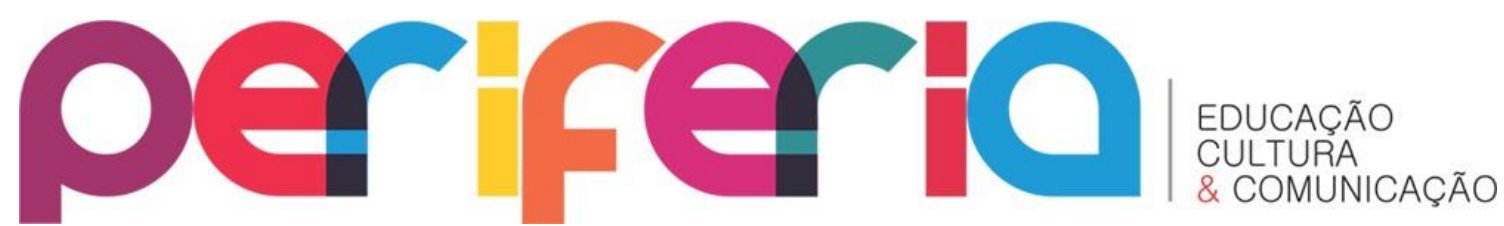

No mesmo ano, pode-se retratar em termos educativos, a primeira escola em solo colonial. De resto, será perceptível que os jesuítas tiveram algumas dificuldades na comunicação com o povo nativo. De acordo com o texto "AS FONTES PORTUGUESAS PARA O CONHECIMENTO DO TUPI ANTIGO (s/d) ":

"Até a chegada dos primeiros missionários jesuítas ao Brasil em 29 de março
de 1549 , não houve nenhuma preocupação com o estudo sistemático da
língua tupi. Falantes brancos da língua havia-os muito na terra naquela época.
Com efeito, esses eram os degredados ou os órfãos que Portugal para cá
enviava. Sem embargo, somente os missionários é que passaram a escrever
naquela língua a partir de então. A primeira leva deles era constituída pelos
padres Manuel da Nóbrega, Azpilcueta Navarro, Leonardo Nunes, Antônio
Rodrigues e por dois irmãos, Vicente Rodrigues e Diogo Jácome. Era o
superior da missão no Brasil o Pe. Nóbrega, mas já em 1553 Inácio de Loyola
criou a Província Jesuítica do Brasil, a primeira do continente americano.
Desde os primeiros anos da novel ordem religiosa era praxe a intensa
atividade epistolar. Por meio das cartas sabemos como se houveram os
primeiros jesuítas com as dificuldades de comunicação com os indígenas." (Id)

No ano de 1553, foi criada a segunda escola que recebeu o nome de Colégio dos Meninos de Jesus de São Vicente.

Em síntese, o Colégio dos Meninos de Jesus de São Vicente foi a instituição educacional que melhor se desenvolveu nessa fase pioneira da educação no Brasil e serviu para pôr em evidência as ricas possibilidades do primitivo plano educacional esboçado por D. João III no Regimento de 1548. (MATTOS, 1958, p. 75 apud NETO, MACIEL, 2008, p.178)

A Companhia de Jesus, através da sua contribuição no contexto educacional, pode ser considerada como um marco inicial à educação brasileira. É visivelmente perceptível o motivo que a Igreja irá apoiar descobrimento de novas terras e consigo a implementação do tipo jesuítico dentro da colônia portuguesa.

A função dos jesuítas nas terras brasileiras era de catequizar os índios e mostrar a salvação que se encontrava na religião, mas num segundo momento, iniciam também uma administração sobre os nativos - pois, o contato e o convívio eram presentes e conquistados com o tempo - aspecto que não agrada a Corte, implicando no desenvolvimento de uma ação complementar favorável aos Jesuítas e não ao Rei, levantando assim, um motivo para a expulsão da Ordem das Terras Brasileiras. (BETILLINI, 2006, p.16) 


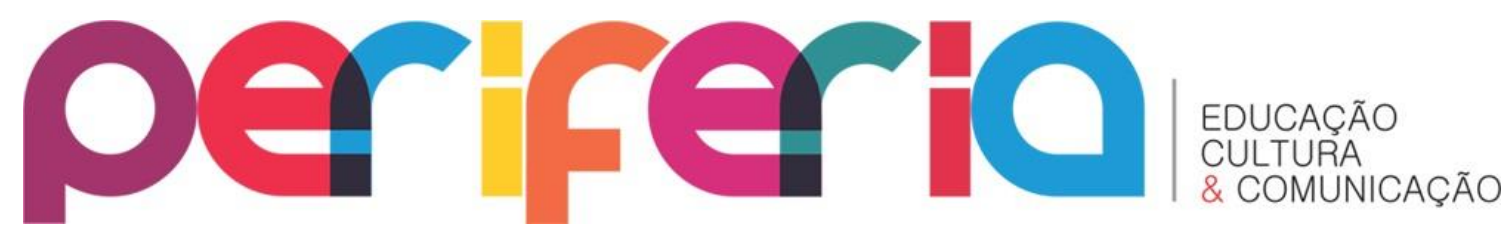

A Companhia de Jesus, através da sua contribuição no contexto educacional, pode ser considerada como um marco inicial à educação brasileira. É visivelmente perceptível o motivo que a Igreja irá apoiar descobrimento de novas terras e consigo a implementação do tipo jesuítico dentro da colônia portuguesa.

\begin{abstract}
A função dos jesuítas nas terras brasileiras era de catequizar os índios e mostrar a salvação que se encontrava na religião, mas num segundo momento, iniciam também uma administração sobre os nativos - pois, o contato e o convívio eram presentes e conquistados com o tempo - aspecto que não agrada a Corte, implicando no desenvolvimento de uma ação complementar favorável aos Jesuítas e não ao Rei, levantando assim, um motivo para a expulsão da Ordem das Terras Brasileiras. (BETILLINI, 2006, p.16)
\end{abstract}

Com a Reforma Protestante, ocorrida aproximadamente no século XV juntamente com a resposta que o clero estará dando com a Contrarreformas, ocorrida dentro do século XV e XVI, a Igreja Católica necessitava de novos seguidores e achou através da Expansão Marítima, as Grandes Navegações, dando os devidos apoios aos países que mandava para as expedições, que acarretava descobrimento de novos espaços, novos territórios. Assim sendo, podendo citar como exemplo o Brasil, a Igreja acaba mandando a Companhia de Jesus que catequizava os indígenas, fazendo-se assim, tornando os nativos seguidores a cultura européia.

A Companhia de Jesus foi fundada em pleno desenrolar do movimento de reação da Igreja Católica contra a reforma protestante, podendo ser considerada um dos principais instrumentos da Contrarreforma nessa luta. Seu objetivo era tentar sustar o grande avanço protestante da época, e para isso utilizou-se de duas estratégias: por meio da educação dos homens e dos índios; e por intermédio da ação missionária, procurando converter à fé católica os povos das regiões que estavam sendo colonizadas. (NETO, MACIEL, 2008, p.172)

De resto, analisando o início da Companhia de Jesus, é possível a identificação do modelo com fins religioso como palavra-chave a catequização dos nativos na iniciação do processo no solo da colônia portuguesa. Ademais, no decorre dos anos a educação ficará como uma das referências dos jesuítas.

Pode-se supor que os jesuítas possuíam um projeto educacional, que, apesar de estar subordinado ao Projeto Português para o Brasil, tinha determinada autonomia, teve papel fundamental e acabou contribuindo para que o Governo português atingisse seus objetivos no processo de colonização e 


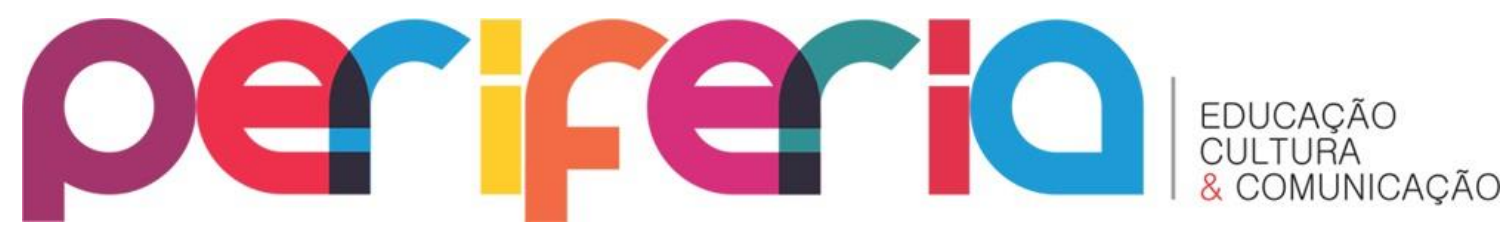

povoamento da colônia brasileira. Os jesuítas formularam seu Projeto Educacional, que denominaremos Projeto Educacional Jesuítico, sendo este o alicerce da nova estrutura social e educacional da Colônia brasileira. (NETO, MACIEL, 2008, p.173)

Contudo, a educação jesuítica vai além da questão de "imposição" a religião europeia. Mas sim, trazer a partir da religião uma forma de libertação de uma cultura que tinha os princípios contrários aos europeus.

Antropologicamente é possível a identificação na Companhia de Jesus, o etnocentrismo. Ou seja, só a sua própria cultura é importante, é a verdadeira. Claro, que é possível encontrar acontecimentos que podem ser ligados a este termo antes da Companhia de Jesus.

Assim, a Companhia de Jesus que educava, catequizava, tinha sim, como uma das finalidades em solo brasileiro colonial trazerem aos nativos luz, libertação através do próprio conhecimento, fazendo assim, a exclusão da cultura indígena.

A religião católica era de grande valor para os portugueses. Além da catequização dos povos indígenas, a ordem cuidava da educação dos filhos dos colonos e da formação dos novos sacerdotes e da elite intelectual da época. Porém a educação não era a meta prioritária dos jesuítas, pois não havia necessidade de uma formação voltada para a agricultura. $O$ projeto educacional jesuítico se propunha a uma transformação social.

A chegada dos jesuítas no Brasil marcava o início das escolas brasileiras, as escolas de "ler e escrever", inicia um processo de criação de escolas ementares, secundárias, seminários e missões, consequentemente é o início do primeiro sistema de ensino organizado, regido pelo Ratio Studiorum. Segundo GADOTTI (2003, p.72): “A Ratio Studiorum é o plano de estudos, de métodos e a base filosófica dos jesuítas. Representa o primeiro sistema organizado de educação católica."

Para os indígenas, o ensino era focado na pacificação e catequização, já para os filhos dos colonos, a educação transpassava a escola elementar, a escola de " ler e escrever". A educação jesuítica encaminhou-se para a formação do homem burguês, desprezando a educação popular. 


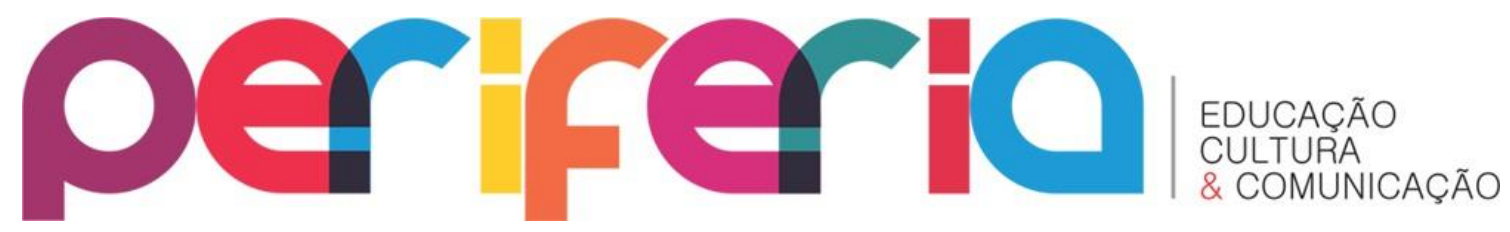

Durante o passar do tempo e novos estudos na área da educação, muitas críticas se levantam no que concerne ao modelo de educação proposto pela ordem dos jesuítas, porém é necessário nos voltarmos aos objetivos e demandas da época, do momento histórico em questão. A educação deveria ir ao encontro dos objetivos da igreja e da coroa portuguesa. Aranha (1996, P.99), afirma que:

Numa época de absolutismo, a igreja, submetida ao poder real, é instrumento importante para a garantia da unidade política, já que uniformiza a fé e a consciência. A atividade missionária facilita sobremaneira a dominação metropolitana e, nessas circunstâncias, a educação assume papel de agente colonizador. (Id)

O projeto educacional regido pela Ratio Studiorum apresentava uma concepção de homem que atendia aos fins educacionais da época. O sistema de ensino obteve êxito na conversão dos índios a fé cristã e o trabalho educativo, bem como aos objetivos doutrinários, econômicos e políticos da coroa portuguesa. Como afirma GADOTTI (2003, p.72) " a ciência do governo para uns e a catequese e a servidão para outros."

\subsection{Composição/Criação do corpo docente}

Quero iniciar este subcapitulo afirmando que a formação de um corpo de educadores se dará também dentro dos muros da escola. A educação jesuítica não se utilizará de formas violentas de punição. O docente jesuíta irá de utilizar como metodologia a virtude. De acordo com VARELA e ALVAREZ (1992, p.79-80):

\footnotetext{
"Produz-se, pois, uma ruptura com relação ao professor das universidades e instituições educativas medievais, como assinala Durkheim, cuja autoridade baseava-se fundamentalmente na posse e transmissão de determinados saberes, enquanto que o professor jesuíta há de ser fundamentalmente um modelo de virtude. “" (Id)
}

O estado em vias de industrialização há de criar escolas especificas para os filhos dos pobres, onde a especificidade das atividades de ensino se á através da origem social. Na escola normal, se formará os professores das classes populares. Só deixando em registro que o professores terão que ser um exemplo de moral. 


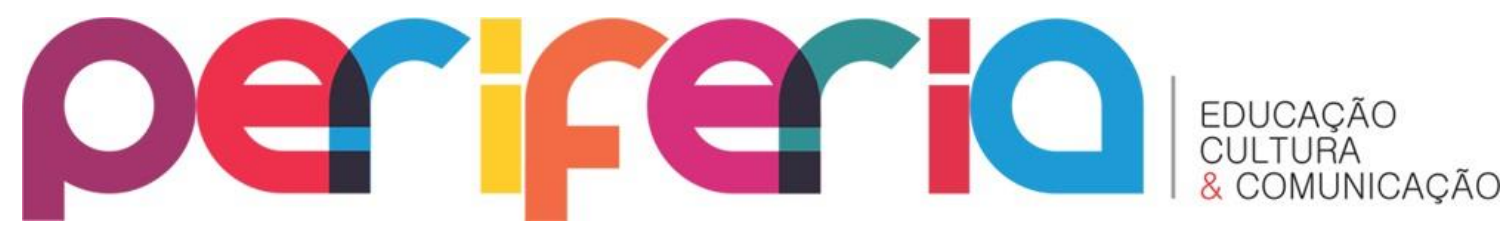

"Disciplinas que os farão acatar a autoridade estabelecida, além de aprender, obedecendo, a "manter enquanto professores, a subordinação e a regularidade entre seus discípulos". Os aprendizes de professor sofrerão um processo intensivo de transformação e vigilância de forma que sua vida privada se imole no altar de sua futura entrega e abnegação à vida pública. " (VARELA e ALVAREZ, 1992, p.81)

Para isso o professor não precisa possuir um saber, mas sim técnicas de domesticação metodológica de intenção da ordem. O professor terá como sua principal tarefa a criação de um cidadão padrão que aceite as ordens sem questionamentos. $\mathrm{O}$ docente será uma espécie de sacerdote que, iluminado por Deus, terá como função evangelizar, "educar" os novos cristões. Portanto, de acordo com o teórico SALGADO (2017, p.8):

\begin{abstract}
"Os fenômenos tidos como educativos se vinculam a perspectivas ideológicas que estabelecem um conjunto de modelos pedagógicos a serem seguidos, que afetam diretamente na vida daqueles que estão se submetendo a algum tipo de formação. Na historiografia educacional brasileira, a influência jesuítica foi apenas o início de um conjunto de práticas que se sucederam e que modificaram e monopolizaram a vida de milhões de indivíduos, nos séculos posteriores. " (Id)
\end{abstract}

\title{
4. Conclusões
}

Através dos levantamentos de dados levantados bibliográficos é possível afirmar que a infância acabou sofrendo com o passar dos tempos mudanças tantos sociais, culturais, até alcançar no século XX, podendo se referir em certo modo sua autonomia. Pois através dos parâmetros político este grupo será entendido como projeto.

O grupo da infância não pode ser tratado, estudada no contexto singular, homogêneo. Mais sim, estudada e referida nos parâmetros plurais e heterogêneos. Pois cada meio, cada espaço possui sua cultura, contudo, suas especialidades, no qual haverá suas variáveis, pontos que diferenciará de espaço a espaço.

No que tange a educação, é de causa urgente pensar numa educação de gratuidade e adaptação a este grupo. Pois ao que se refere ao currículo, é perceptível onde a criança que tem se adaptar. De resto, avaliação em séries iniciais, no qual, creio que o método avaliativo deveria ser pautado pelo que se refere o referencial teórico TYLER (1977), que tinha como método avaliativo a participação. Porque não avaliar a partir do brincar, do lúdico? 


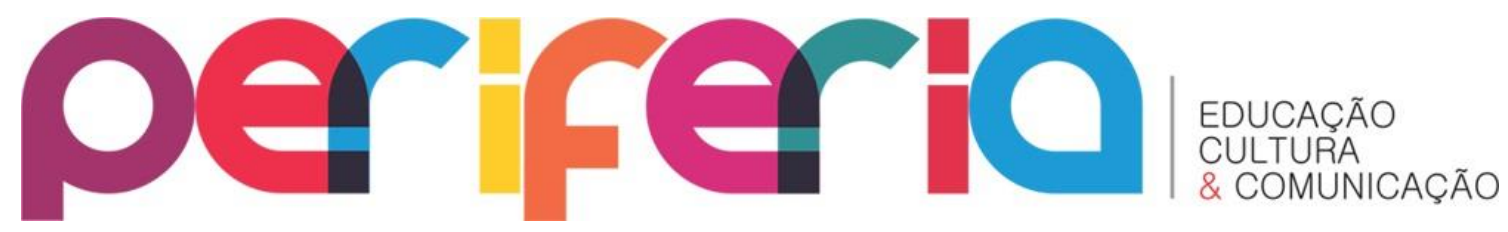

O modelo educacional dos jesuítas teve uma grande importância para a história da educação brasileira, pois foi o primeiro sistema de ensino organizado no Brasil de acordo com a Ratio Studiorum, conjunto de normas que regulamentava todo o ensino jesuíta. O modelo pregado pela companhia de Jesus tinha suas particularidades, seus objetivos, crenças, visão de homem e mundo. Era objetivo maior da ordem, catequizar os povos que aqui já viviam e a partir dessa catequização surge a demanda educacional.

Percebe-se na educação jesuítica uma separação entre indígenas e colonos. A educação, os colégios jesuítas, era dedicada para a elite, para os filhos dos colonos, era a formação burguesa. Já para os indígenas, o foco era a formação catequética.

Apesar dos desafios encontrados ao longo da história da educação jesuítica em terras brasileiras, a companhia obteve êxito de acordo com seus objetivos e visão de homem e mundo. A ordem dos jesuítas promoveu a transformação social que se propunha, com a catequização dos povos indígenas e a formação burguesa, dando início ao processo de criação de escolas elementares, secundárias, seminários e missões, espalhados pelo Brasil.

\section{Bibliografias}

AS FONTES PORTUGUESAS PARA O CONHECIMENTO DO TUPI ANTIGO. São Paulo:USP, [s/a]. Disponível em: <http://tupi.fflch.usp.br/sites/tupi.fflch.usp.br/files/AS\%20FONTES\%20PORTUGUES AS\%20PARA\%200\%20CONHECIMENTO\%20DO\%20TUPI\%20ANTIGO.pdf $>$. Acesso em: 25 out. 2017.

ARANHA, Maria Lúcia de A. A história da educação. São Paulo: Moderna, 1996.

ARIÉS, Philippe. História Social da Criança e da Família. 2. ed. Tradução de Dora Flaksman. Rio de Janeiro: LTC Editora, 1981.

BENJAMIN, Walter. O narrador: considerações sobre a obra de Nikolai Leskov. In: BENJAMIN, Walter. Magia e técnica, arte política: ensaios sobre a literatura e história da cultura. 7. Ed. São Paulo: Brasiliense, 1994. (Obras Escolhidas v.1)

BETTILINI, Rita Filomena Andrade Januário.A COMPANHIA DE JESUS, DAS ORIGENS AO OCASO: UMA PROPOSTA DE ANÁLISE HISTORIOGRÁFICA. Revista HISTEDBR On-line, Campinas, n.22, p. 13 -25, jun. 2006. Link de 


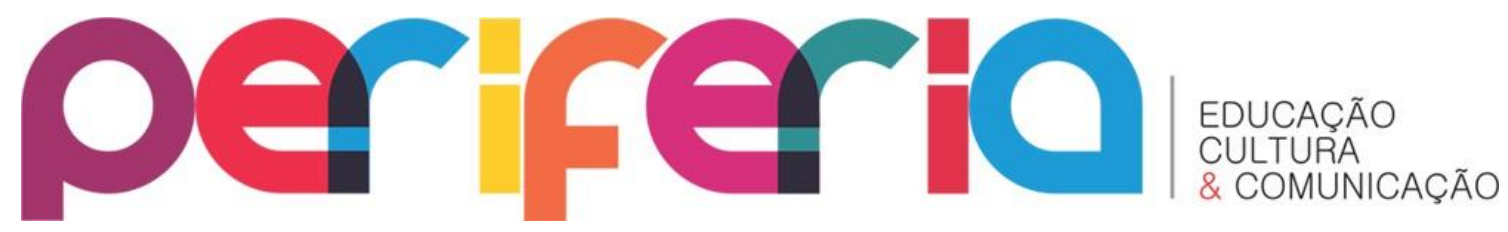

acesso:http://www.histedbr.fe.unicamp.br/revista/edicoes/22/art02_22.pdfAcesso em: 25 out. 2017.

BORBA, Ângela M. O brincar como um modo de ser e estar no mundo. In: BRASIL, MEC/SEB Ensino fundamental de nove anos: orientações para a inclusão da criança de seis anos de idade. organização Jeanete Beauchamp, Sandra Denise Rangel, Aricélia Ribeiro do Nascimento - Brasília: Ministério da Educação, Secretaria de Educação Básica, 2006

DIOLIVEIRA, Sinésio. Palavras de ouro sobre a importância da Educação. CERRADO, Goiânia, 01 mar. 2016. 1, p. 2. Disponível em: . Acesso em: 20 jul. 2017. Aput DOMINGUES, J. M.. Devir-criança e seu significado da educação na infância. 2017. In: V Seminário Internacional de Pesquisa com o tema: dimensões da privatização na Educação Básica, 2017, Ribeirão Preto. Grupo de Estudos e Pesquisa em Política Educacional, Ribeirão Preto: USP, 2017. v. I. p. 388-393

DOMINGUES, J. M.. Devir-criança e seu significado da educação na infância. 2017. In: V Seminário Internacional de Pesquisa com o tema: dimensões da privatização na Educação Básica, 2017, Ribeirão Preto. Grupo de Estudos e Pesquisa em Política Educacional, Ribeirão Preto: USP, 2017. v. I. p. 388-393

GADOTTI, Moacir. História das ideias pedagógicas. São Paulo: Editora Ática, 2003.

KOHAN, W. O. A infância da educação: o conceito devir-criança. In: KOHAN, W. (Org.). Lugares da Infância. Rio de Janeiro: DP\&A, 2004.

NETO, Alexandre Shigunov e MACIEL Lizete Shizue Bomura.O ensino jesuítico no período colonial brasileiro algumas discussões. Curitiba: UFPR, 2008. Disponível em: <http://revistas.ufpr.br/educar/article/view/12806/8694>. Acesso em: 25 out. 2017.

PROUT, Alan. Participação, políticas e as condições da infância em mudança. Infância em perspectiva: políticas, pesquisas e instituições. Müller, Fernanda (org.) São Paulo: cortez, 2010. $256 \mathrm{p}$.

SALGADO, Diego Dias. Os jesuítas e as terras coloniais brasileiras: conflitos socioculturais em questão.IX Seminário Internacional Redes Educativas e Tecnologias. Rio de Janeiro. UERJ,2017. Link de acesso:http://www.seminarioredes.com.br/ixredes/adm/trabalhos/diagramados/TR283.p dfAcesso em: 25 out. 2017.

TYLER, Ralph. Princípios básicos de currículo e ensino. Porto Alegre. Globo, 1977.

VASCONCELLOS, TÂNIA. Infância e Narrativa. In: VASCONCELLOS, T. (Org).

Reflexões sobre infância e cultura. Niterói: EdUFF, 2008.

VARELA, Júlia; ALVAREZ-URIA, Fernando. A maquinaria escolar. Teoria e Educação. Porto Alegre: Pannonica, n. 6, 1992, p. 68-96

Revista Periferia, v.10, n.1, p. 33 - 46, Jan./Jun. 2018 